\title{
nature
}

Vol 438 | Issue no. 7069 | 8 December 2005

\section{Unapproved tests on a chip}

\author{
Prenatal genetic tests can now check for abnormalities in developing fetuses, \\ but there is still no regulatory framework for them in the United States.
}

下 or more than a decade, genetic tests have been on the way that would tell patients about genetic variations that might increase their susceptibility to disease. And all the while, bioethicists have been warning the US government of the impending need to regulate such tests when they arrive. Now hundreds of these tests are available, including powerful prenatal tests that use microarrays to scan hundreds of genes in unborn children. Yet despite the warnings, the tests remain effectively unregulated.

Last December, Affymetrix of Santa Clara, California, became the first company to get approval from the US Food and Drug Administration (FDA) for a microarray chip for use as such a diagnostic device. The chip can check for genetic differences that might predict a patient's tolerance to drug treatment. Now, researchers at Baylor College of Medicine in Houston, Texas, are offering pregnant women a genome-scanning test that checks for abnormalities in developing fetuses (see page 733). But because of the way this test was developed, it is not currently subject to FDA review - and neither are tests made by private companies that can do prenatal screening but haven't yet been used to do so. The FDA has declined to say whether it intends to review these sorts of tests.

One major point of confusion is whether the FDA has the power to regulate tests that are developed within a particular laboratory and are then used only in that lab, without being sold to outsiders. In 1997 , the agency said that it would regulate these 'home brew' tests under the same rules that it uses to regulate other medical devices. But in 2003, when it issued further guidance on the ingredients that are used to make home brews, it decided that it didn't have the power to regulate them after all. Instead, the FDA said it would regulate only the 'analyte-specific reagents' - the ingredients, such as antibodies or nudeotide sequences, that make up the test. And it will only regulate the analyte-specific reagents if they are sold to the maker of the test; if the reagents are developed in-house, neither the reagents nor the test are subject to regulation by the FDA.

Companies that sell microarrays for others to use in genetic tests do have to register with the FDA, and must submit information supporting their ability to make the arrays properly to the regulator for approval. These rules also hold for companies or labs that make key components of genetic tests, such as gene probes. However, private labs that make and use their own microarrays for genetic testing are not subject to FDA scrutiny.

Additionally, some companies are stretching the interpretation of the rules by marketing genetic tests that may be of dubious value (see Nature 426, 107 ; 2003). Because the companies make and use their own testing materials, they don't have to register under the regu-
"The unfortunate end result is a free-for-all in the marketing of genetic tests to the public, aswell as widespread confusion among researchers and laboratories." lations governing companies that sell microarrays to others. The unfortunate end result is a free-for-all in the marketing of genetic tests to the public, as well as widespread confusion among researchers and laboratories about their regulatory obligations.

The introduction of prenatal microarray tests into this picture creates additional urgency for the regulators to act. If misdiagnoses occur, children may be born with an unexpected disease, or fetuses may be terminated on the basis of false information. Let's hope that such episodes don't have to be documented before the FDA acts to clarify its role as a regulator of genetic testing. If the agency finds that it lacks the authority to properly supervise the makers and users of home-brew genetic tests, then Congress should intervene to grant it that authority.

\section{Launching a business}

\section{There's little evidence that commercial approaches can radically reduce the cost of getting into space.}

thas long been an item of faith among some space aficionados in the United States that private enterprise can, if given the chance, sharply reduce the cost of rocket launches. For this vocal group, the government - and NASA in particular - has always been the enemy. What's necessary, they believe, is a commercial launch business unfettered by bureaucratic oversight.

The emergence of such a business has been hampered by its limited range of customers. A few operators of commercial telecommunication satellites aside, the only reliable customers for would-be rocket makers in the United States are government agencies, primarily NASA and the Department of Defense. In the 1990s, it looked for a while as though the satellite business might rapidly expand, as plans were laid to have swarms of small communications satellites circling the Earth. A number of would-be rocket builders opened offices, hoping to capture some of that business. But when the new satellite businesses failed to materialize, the rocket companies disappeared.

Today, the most prominent player in the private rocket business is Internet tycoon Elon Musk, whose California-based company SpaceX has pledged to bring down the cost of launching materials into orbit by an order of magnitude (see page 736).

Musk starts with several advantages. His rocket, Falcon 1 , which is sitting on the Kwajalein atoll in the Pacific awaiting its first launch, was produced by a small design team. It doesn't have the overheads of the large corporations such as Boeing or Lockheed Martin that 